\title{
Efeito da idade de desmame no desenvolvimento e nas características de carcaça de novilhos de corte
}

\section{José Fernando Piva Lobatoํㅜ, Luciane Salgueiro Pio de Almeida², Eduardo Baptista Osório³, Alejandra Müller ${ }^{4}$}

\author{
1 Departamento de Zootecnia - UFRGS. Caixa Postal 15.100, CEP: 90001-970. Bolsista do CNPq. \\ ${ }^{2}$ M.Sc. em Zootecnia - UFRGS, Porto Alegre, RS. \\ ${ }^{3}$ Engenheiro Agrônomo - UFRGS, Porto Alegre, RS \\ ${ }^{4}$ Ministério da Agricultura, Porto Alegre, RS.
}

\begin{abstract}
RESUMO - Avaliou-se o efeito da idade de desmame no desempenho e nas características de carcaça de bezerros filhos de vacas cruzas zebuínas x taurinas, primíparas aos 3 anos de idade. As vacas foram mantidas durante dois invernos/primaveras, do desmame à primeira estação de monta, em pastejo rotativo em dois grupos (ponta e rapador), em pastagens de azevém anual (Lolium multiflorum Lam) e trevo vesiculoso (Trifolium vesiculosum cv. Yuchi) e, posteriormente, durante o verão e o outono, em campo nativo. Os bezerros foram distribuídos aleatoriamente, segundo o grupo racial e o grupo de pastejo das vacas, em duas idades de desmame: desmame precoce $(\mathrm{DP})=$ sete bezerros desmamados aos 70 dias de idade com 83,2 $\mathrm{kg}$ de PV médio; e idade convencional $(\mathrm{DC})=\mathrm{dez}$ bezerros desmamados com 180 dias de idade e 152,0 kg de PV médio. O delineamento experimental foi o completamente casualizado. Os novilhos foram abatidos aos 2 anos de idade. O grupo de manejo das vacas (ponta ou rapador) não teve efeito sobre o desempenho e as características de carcaça dos novilhos. Os animais do desmame convencional foram mais pesados até 1 ano de idade ( $\mathrm{DP}=183,0 \mathrm{~kg}$ vs $\mathrm{DC}=202,1 \mathrm{~kg}$ ), mas não diferiram dos demais quando abatidos aos 2 anos de idade ( $\mathrm{DP}=411,2 \mathrm{~kg}$ vs $\mathrm{DC}=408,5 \mathrm{~kg}$ ). As carcaças não diferiram quanto ao acabamento, à conformação, à classificação "Cota Hilton" e ao rendimento. Portanto, o desmame precoce não influenciou o desenvolvimento e as características de carcaça ao abate aos 2 anos de idade.
\end{abstract}

Palavras-chave: crescimento compensatório, desmame precoce, pastagens melhoradas, suplementação

\section{Effect of weaning age on growth and carcass characteristics of beef steers}

\begin{abstract}
The objective of this trial was to evaluate the effect of weaning age on growth and carcass characteristics of calves from primiparous Bos indicus x Bos taurus crossbred cows. Heifers were divided in two groups according to the order of access to pasture and rotationally grazed pastures of ryegrass (Lolium multiflorum Lam) and arrowleaf clover (Trifolium vesiculosum cv. Yuchi) from weaning until their first mating season (two winter/spring seasons); animals were then transferred to native pasture in the following summer-autumn season. Calves were randomly assigned, according to breed and heifers grazing group order, to one of two weaning ages: early weaning (EW) - 07 calves weaned at 70 days of age with an average body weight of $83.2 \mathrm{~kg}$ or conventional weaning (CW) -10 calves weaned at 180 days of age and with an average body weight of $152.0 \mathrm{~kg}$ in a completely randomized design. Steers were slaughtered with two years of age. Heifers grazing group did not affect calves performance. Calves in the $\mathrm{CW}$ treatment were heavier $(202.1 \mathrm{~kg})$ at one year old than those on EW $(183.0 \mathrm{~kg})$, but no significant difference was observed when animals were slaughtered at two years of age $(\mathrm{CW}=408.5 \mathrm{~kg}$ vs. $\mathrm{EW}=411.2 \mathrm{~kg})$. Carcass traits such as fat thickness, conformation, "Hilton Quote" classification, and hot yield did not differ comparing EW with CW steers. Therefore, early weaning did not affect performance and carcass characteristics of steers slaughtered at two years of age.
\end{abstract}

Key Words: compensatory growth, early weaning, improved pastures, supplementary feeding

\section{Introdução}

O desmame precoce é uma prática de manejo utilizada para incrementar os índices reprodutivos dos rebanhos de cria por meio da redução da exigência energética da vaca em situações de excesso de carga animal (Simeone \& Lobato,
1996) e de vacas com baixa condição corporal (Pio de Almeida et al., 2002). A eficiência da transformação de forragem em leite e de leite em crescimento do bezerro é de apenas 5 a $7 \%$ (Rovira, 1996).

Cachapuz et al. (1990) avaliaram os efeitos da utilização de diferentes tipos de suplementação alimentar em pastagem 
nativa ou em pastagem melhorada no inverno, em comparação a pastagem nativa, sobre o comportamento reprodutivo de vacas e o desenvolvimento de seus bezerros. Esses autores observaram que a porcentagem de prenhez nas vacas mantidas em pastagem nativa melhorada foi maior que naquelas mantidas somente em pastagem nativa. Nas condições do trabalho, as vacas mantidas em pastagem nativa sem suplementação perderam peso, chegaram ao parto com baixa condição corporal, pariram bezerros mais leves e não conceberam no período de acasalamento subseqüente.

A sucção do leite e a presença do bezerro criam mensagens metabólicas, neurais (sensoriais e olfatórias) e fisiológicas, que, combinadas, inibem o pulso gerador no hipotálamo determinando a inibição da secreção de GnRH (Williams et al., 1996). Short et al. (1990) citaram metabólitos circulantes no sangue, como a glicose, fazendo parte do mecanismo de controle conhecido como sistema peptídeo opióide endógeno. Este sistema, no cérebro e no hipotálamo, pode traduzir parcialmente as mensagens geradas pelo ato da mamada em efeito inibitório na descarga de $\mathrm{GnRH}$.

Poucos experimentos têm sido realizados para demonstrar a viabilidade do desmame precoce em relação ao desenvolvimento e às características de carcaça dos bezerros. Moraes \& Lobato (1993) desmamaram bezerros aos 147 dias e aos 209 dias de idade e abateram os novilhos de ambos os tratamentos com aproximadamente 16 meses de idade e $400 \mathrm{~kg}$ de PV.

Albospino \& Lobato (1994) estudaram o efeito do desmame de bezerros aos 100 dias (S1) e aos 150 dias (S2) de idade sobre o desenvolvimento até o abate aos 24/26 meses de idade. Os pesos vivos no frigorífico e os rendimentos de carcaça dos novilhos foram de $400 \mathrm{~kg}$ e $56,1 \%$ para $\mathrm{S} 1$ e de $398 \mathrm{~kg}$ e $56,1 \%$ para $\mathrm{S} 2(\mathrm{P}>0,05)$. Esses autores concluíram ser viável o abate de novilhos precoces desmamados aos 100 dias de idade mediante eficiente programa sanitário e a utilização de pastagens de azevém e trevo vesiculoso nos dois primeiros invernos/primaveras. Pio de Almeida et al. (2003) desmamaram bezerros aos 91 dias (desmame precoce) ou aos 170 dias de idade (desmame à idade convencional) e obtiveram pesos médios de 414,0 e $432,3 \mathrm{~kg}$ ( $\mathrm{P}>0,05)$, quando o abate foi realizado aos 25/26 meses de idade dos bezerros desmamados precocemente ou à idade convencional, respectivamente.

Restle et al. (1999b) estudaram as características de carcaça de machos 3/8 Nelore 5/8 Hereford desmamados em duas idades, aos 72 e aos 210 dias de idade. Os bezerros foram terminados em confinamento e abatidos aos 14 meses de idade e não diferiram $(\mathrm{P}>0,05)$ quanto ao peso de fazenda e rendimento de carcaça quente $(72$ dias $=424 \mathrm{~kg}$ e $54,7 \% ; 210$ dias $=406 \mathrm{~kg}$ e $54,4 \%$ ) e quanto ao peso de carcaça fria ( 72 dias $=224 \mathrm{~kg}$ e 210 dias $=214 \mathrm{~kg})$. A espessura de gordura de cobertura também não diferiu ( $\mathrm{P}>0,05)$ entre os dois grupos, sendo obtidos valores de 4,6 e 4,2 mm para os animais desmamados aos 72 dias e 210 dias, respectivamente.

A recuperação dos animais desmamados precocemente pode ser atribuída ao ganho compensatório apresentado por esses animais. Meyer et al. (1965) e O'Donovan et al. (1972) demonstraram que a qualidade da forragem após o período de restrição é de grande importância para os animais expressarem ganho compensatório, que depende da natureza, da duração da restrição e da interação entre dessas características (Drouillard et al., 1991).

Objetivou-se neste estudo avaliar os efeitos de duas idades de desmame (precoce - 70 dias de idade e convencional - 180 dias de idade) no desenvolvimento de bezerros até os 2 anos de idade mantidos por dois períodos de invernoprimavera em pastagens de ciclo hiberno/primaveril.

\section{Material e Métodos}

O experimento foi conduzido no período de março de 1996 a 19/11/98 na Estação Experimental Agronômica da Universidade Federal do Rio Grande do Sul, situada no km 146 da BR 290, em Eldorado do Sul, na Depressão Central do Rio Grande do Sul. Foram utilizados 17 bezerros filhos de vacas cruzas zebuínas $\times$ taurinas, primíparas aos 3 anos de idade, mantidas durante os dois primeiros invernos/primaveras em pastagens melhoradas de azevém anual (Lolium multiflorum Lam) e trevo vesiculoso cv. Yuchi (Trifolium vesiculosum cv. Yuchi), em pastejo rotativo em dois grupos (ponta e rapador) e, posteriormente, em campo nativo em grupo único.

O clima da região é do tipo Cfa (subtropical úmido) segundo classificação de Köppen (Bergamaschi \& Guadagnin, 1990) e a precipitação média anual é de $1.400 \mathrm{~mm}$, com menor incidência nos meses de verão. O solo classificado como laterítico bruno avermelhado distrófico (Brasil, 1973) - pertence à unidade de mapeamento São Jerônimo, classificado como laterítico bruno avermelhado distrófico (Brasil, 1973), e possui textura franco-argilosa a argilosa, constituindo solo ácido, pobre em matéria orgânica e com pH em torno de 5,0.

A pastagem nativa é composta de espécies dos gêneros Andropogon, Axonopus e Paspalum, com leguminosas como Trifolium polimorphum e Desmodium incanum. Há 
espécies cespitosas de baixo valor forrageiro, como Eryngium horridum (caraguatá), Baccharis trimera (carqueja) e Baccharis coridifolia (mio-mio) (Boldrini, 1993).

Durante o experimento, foram colhidas dos potreiros, ao acaso, 18 amostras de forragem. Estimativas da forragem disponível foram realizadas e classificadas segundo escala de 1 a 5 , em que $1=$ menor e $5=$ maior disponibilidade. $O$ corte de forragem foi feito rente ao solo com um quadrado de $50 \times 50 \mathrm{~cm}$ e as amostras foram tomadas em cada potreiro antes da entrada dos animais (Gardner, 1967). O material colhido foi identificado conforme o potreiro e o dia de colheita e as amostras foram mantidas em estufa a $60^{\circ} \mathrm{C}$ até peso constante para determinação da MS, sendo posteriormente moídas e acondicionadas em sacos plásticos até a realização das análises químicas pelo Laboratório de Nutrição Animal da Faculdade de Agronomia da UFRGS. Foram formadas subamostras classificadas como $1+2$ e $4+5$ para determinação do teor de $\mathrm{PB}$; o parâmetro 3 foi utilizado apenas para determinação do conteúdo de MS (AOAC, 1975).

Foram avaliadas duas idades de desmame: desmame precoce (DP) - sete bezerros desmamados em 14/11/96, aos 70 dias de idade, com peso mínimo de $70 \mathrm{~kg}$ e aproximadamente $83,2 \mathrm{~kg}$; desmame convencional (DC) - dez bezerros desmamados em 11/03/97, aos 180 dias de idade, com $152,0 \mathrm{~kg}$ de PV. Os bezerros do desmame precoce foram mantidos durante quatro dias pós-desmame em potreiro com água e concentrado com $18 \%$ de PB à vontade. No quinto dia, foram encaminhados para potreiros diferidos previamente por 40 dias com azevém em pós-florescimento, trevo vesiculoso em florescimento e capim-bermuda (Cynodon dactilum), onde receberam o mesmo concentrado por 60 dias. Posteriormente, foram mantidos em pastagem nativa no mesmo potreiro dos bezerros do desmame convencional.

No período de 28/05/97 a 03/07/97, todos os bezerros receberam suplementação com $1,5 \mathrm{~kg}$ de concentrado ( $80 \%$ de milho e $20 \%$ de soja moída), além de silagem à vontade.

Nos dois períodos de inverno/primavera (o primeiro de 04/07/97 a 12/11/97 e o segundo de 23/05/98 a 14/11/98), os animais foram mantidos em potreiros de pastagem nativa melhorada com aveia (Avena sativa), azevém e trevo vesiculoso em pastejo rotativo.

Todas as pesagens foram realizadas com 14 horas de jejum de sólidos e líquidos.

Os animais foram abatidos em 19/11/98 e cada carcaça foi classificada visualmente quanto ao grau de acabamento (em mm de gordura), à conformação $(\mathrm{C}=$ convexa, $\mathrm{Sc}=$ subconvexa, $\mathrm{Re}=$ retilínea, $\mathrm{Sr}=$ sub-retilínea e $\mathrm{Co}=$ côncava) e à classificação geral. Segundo o Sistema
Nacional de Tipificação de Carcaças Bovinas (Brasil, 1989), a carcaça é considerada "Cota Hilton" (classificação superior) quando proveniente de um animal de até quatro dentes definitivos, sem queda dos segundos médios da primeira dentição, e apresenta acabamento de 2 a $4 \mathrm{~mm}$ de gordura, conformação Re, Sc ou Ce peso líquido mínimo de carcaça quente de $210 \mathrm{~kg}$ (machos inteiros ou castrados) ou $180 \mathrm{~kg}$ (fêmeas). Além desses aspectos visuais, foram determinados os pesos líquidos e os rendimentos de carcaça quente individualmente.

O delineamento experimental utilizado foi o completamente casualizado. Os dados foram analisados pelo General Linear Models (GLM) do programa Statistical Analysis System (SAS, 1996). As variáveis de resposta contínua com distribuição pressuposta normal foram analisadas por análise de (co)variância, considerando o desbalanceamento do número de observações, utilizando-se o modelo a seguir:

$$
\mathrm{Y}_{\text {hijk }}=\mu+\mathrm{D}_{\mathrm{h}}+\mathrm{G}_{\mathrm{i}}+\mathrm{T}_{\mathrm{j}}+\mathrm{b}(\mathrm{P})+\mathrm{e}_{\mathrm{hijk}}
$$

em que $Y_{\text {hijk }}=$ variável-resposta associada ao k-ésimo animal; $\mu=$ média geral; $D_{h}=$ efeito fixo do h-ésimo tipo de desmame; $\mathrm{G}_{\mathrm{i}}=$ efeito fixo do i-ésimo grupo racial materno; $\mathrm{T}_{\mathrm{j}}=$ efeito fixo do j-ésimo tratamento inicial das mães; $\mathrm{b}(\mathrm{P})=$ coeficiente de regressão do peso ao DP; $\mathrm{e}_{\mathrm{hijk}}=$ efeito residual aleatório.

$\mathrm{Na}$ análise do desmame precoce, utilizou-se como covariável a DJP em sustituição ao P. As variáveis classificatórias da carcaça foram analisadas pelo teste quiquadrado (Gomez \& Gomez, 1984), segundo o modelo:

$$
\mathrm{Y}_{\mathrm{hi}}=\mu+\mathrm{D}_{\mathrm{h}}+\mathrm{e}_{\mathrm{hi}}
$$

em que: $\mathrm{Y}_{\mathrm{hi}}=$ variável-resposta associada ao i-ésimo animal; $\mu=$ média geral; $D_{h}=$ efeito fixo do h-ésimo tipo de desmame; $\mathrm{e}_{\mathrm{hi}}=$ efeito residual aleatório.

\section{Resultados e Discussão}

$\mathrm{Na}$ Tabela 1 são apresentados, em kg, os pesos médios dos bezerros do desmame precoce (14/11/96) e do desmame convencional (11/03/97), em 25/09/97, 12/11/97, 23/05/98 e 14/11/98 (aos 2 anos de idade).

Em 11/03/97, os bezerros do desmame precoce apresentaram peso menor que o daqueles do desmame convencional, provavelmente em decorrência do estresse do desmame ao qual foram submetidos. Restle et al. (1999a) afirmaram que bezerros desmamados precocemente não têm o sistema digestivo completamente desenvolvido e, portanto, não obtêm da pastagem quantidade de nutrientes suficiente para manter os ganhos de peso apresentados quando ao pé da vaca.

Durante a amamentação, a absorção nos intestinos de leite ou substitutos consiste na principal fonte de energia 
Tabela 1 - Média dos pesos vivos (em $\mathrm{kg}$ ) dos novilhos do desmame precoce (DP) e do desmame convencional (DC) em 25/09/97, $12 / 11 / 97,23 / 05 / 98$ e 14/11/98 (2 anos de idade)

Table 1 - Average body weights ( $\mathrm{kg}$ ) of calves early weaned (EW) and conventionally weaned (CW) at 09/25/97, 11/12/97, 05/23/98 and at two years old (11/14/98)

\begin{tabular}{|c|c|c|c|c|c|c|}
\hline $\begin{array}{l}\text { Idade de desmame } \\
\text { Weaning age }\end{array}$ & $\begin{array}{l}\text { DP } 14 / 11 / 96 \\
\text { EW } 11 / 14 / 96\end{array}$ & $\begin{array}{c}\text { DC } 11 / 03 / 97 \\
\text { CW } 03 / 11 / 97\end{array}$ & $\begin{array}{c}25 / 09 / 97 \\
09 / 25 / 97\end{array}$ & $\begin{array}{c}12 / 11 / 97 \\
11 / 12 / 97\end{array}$ & $\begin{array}{c}23 / 05 / 98 \\
05 / 23 / 98\end{array}$ & $\begin{array}{r}14 / 11 / 98 \\
11 / 14 / 98\end{array}$ \\
\hline $\begin{array}{l}\text { DC (180 dias }) \\
C W \text { (180 days })\end{array}$ & 81,5 & $152,0 \mathrm{a}$ & $202,1 \mathrm{a}$ & 233,2 & 272,8 & 408,5 \\
\hline $\begin{array}{l}\text { DP }(70 \text { dias }) \\
E W(70 \text { days })\end{array}$ & 83,2 & $134,4 b$ & $183,0 \mathrm{~b}$ & 221,3 & 246,6 & 411,2 \\
\hline
\end{tabular}

Médias seguidas de mesma letra, na mesma coluna, não diferem $(P>0,05)$ pelo F-teste.

Means followed by the same letter, in a column, do not differ $(P>0.05)$ by F-test.

e proteína. Entretanto, o desmame causa alterações na disponibilidade de nutrientes, de modo que a energia origina-se primariamente da fermentação ruminal e da absorção protéica nos intestinos de proteínas não-degradadas e microbianas (Funaba et al., 1994).

Os bezerros do desmame precoce apresentaram menor peso até 1 ano de idade (25/09/97). No entanto, os pesos obtidos a partir de 12/11/97 foram estatisticamente semelhantes até os 2 anos de idade. Resultados semelhantes foram obtidos por Pio de Almeida et al. (2003), em animais desmamados aos 91 dias ou aos 170 dias de idade. Os animais do desmame precoce foram estatisticamente mais leves até 1 ano de idade $(414,0 \mathrm{~kg})$, mas apresentaram desenvolvimento semelhante $(\mathrm{P}>0,05)$ aos do desmame convencional aos 2 anos de idade $(432,3 \mathrm{~kg})$.

Simeone \& Lobato (1998) também observaram, em condições de baixa oferta de forragem, menores pesos $(\mathrm{P}<0,05)$ aos 365 dias em bezerros 1/2 Red Angus 1/4 Nelore 1/4 Hereford desmamados aos 90 dias $(158,1 \mathrm{~kg}$ de PV e 0,262 kg de GMD) em comparação àqueles desmamados aos 180 dias de idade (177,8 kg de PV e 0,210 kg de GMD).

Poppi \& McLennan (1995) observaram maior eficiência alimentar em animais alimentados adequadamente quando submetidos previamente à restrição alimentar. Essa maior eficiência pode ser decorrente do consumo de EM superior às exigências de mantença, o que acarreta maior deposição protéica, maior eficiência alimentar e maior ganho de peso.

Como demonstrado na Tabela 2 , no período total do desmame precoce ao desmame convencional, o ganho médio diário (GMD) dos animais do desmame precoce $(0,444 \mathrm{~kg})$ foi inferior $(\mathrm{P}<0,05)$ ao daqueles do desmame convencional $(0,595 \mathrm{~kg})$.

Os ganhos médios diários no período do desmame precoce ao desmame convencional estão de acordo com os encontrados por Moraes \& Lobato (1993), que obtiveram GMD de 0,88 kg em bezerros Polled Hereford e cruzas Nelore x Polled Hereford desmamados aos 7 meses e de $0,33 \mathrm{~kg}$ do desmame aos 5 meses até os 7 meses de idade.
No primeiro outono-inverno-primavera, os ganhos médios diários dos animais do desmame precoce $(0,363 \mathrm{~kg})$ e do desmame convencional $(0,331 \mathrm{~kg})$ não diferiram $(\mathrm{P}<0,05)$. Valores semelhantes foram obtidos por Albospino \& Lobato (1994), no período primavera-verão-outono, em bezerros desmamados aos $100(0,248 \mathrm{~kg})$ ou aos 150 dias de idade $(0,214 \mathrm{~kg})$.

No segundo outono-inverno-primavera, os animais do desmame precoce $(0,941 \mathrm{~kg})$ apresentaram ganhos superiores $(\mathrm{P}<0,05)$ aos obtidos nos novilhos do desmame convencional $(0,775 \mathrm{~kg})$. A recuperação no desenvolvimento apresentada pelos animais do desmame precoce pode ser considerada crescimento compensatório, observado em animais realimentados após período de restrição nutricional. Esta restrição não significa perda de peso, e sim redução no ganho médio diário dos animais (Phillips et al., 1991).

O ganho médio diário nos animais do desmame precoce ao segundo ano de idade $(0,453 \mathrm{~kg})$ também não diferiu $(\mathrm{P}>0,05)$ do obtido naqueles do desmame convencional $(0,450 \mathrm{~kg})$, comprovando que os animais desmamados precocemente têm ganho compensatório quando em pastagens nativas melhoradas, apresentando GMD e pesos vivos aos 2 anos de idade compatíveis com os dos animais desmamados à idade convencional.

Carstens et al. (1991) avaliaram animais durante terminação em confinamento e verificaram que os animais em ganho compensatório apresentaram maior rendimento de carcaça $(\mathrm{P}<0,01)$, menor peso do trato gastrintestinal, maior porcentagem de proteína, água e cinzas e, ainda, 25\% menos gordura na carcaça.

Neste estudo, os novilhos dos dois tratamentos não diferiram significativamente $(\mathrm{P}>0,05)$ quanto ao peso vivo ao abate (PVA), ao peso líquido de carcaça quente (PLC) e ao rendimento de carcaça (RCQ) (Tabela 3). Resultados semelhantes foram obtidos por Pio de Almeida et al. (2003) em bezerros desmamados aos 91 dias (414,0 kg de PVA e $50,2 \%$ de RCQ) ou aos 170 dias de idade (432,3 kg de PVA e 50,0\% de RCQ) e abatidos aos 2 anos de idade. Albospino 
Tabela 2 - Ganhos médios diários (em kg) do desmame precoce ao desmame convencional, do desmame precoce até 12/11/97, no primeiro e no segundo período outono-inverno-primavera e do desmame precoce aos 2 anos de idade

Table 2 - Average daily weight gains ( $k g$ ) from early weaning (EW) to conventional weaning (CW), from EW to 11/12/97, in the first (03/11/97 to 11/12/97) and second (05/23/98 to 11/14/98) autumn-winter-spring seasons, and from EW to two years old (11/14/98)

\begin{tabular}{|c|c|c|c|c|c|}
\hline $\begin{array}{l}\text { Idade de desmame } \\
\text { Weaning age }\end{array}$ & $\begin{array}{c}\text { DP-DC } \\
(14 / 11 / 96 \text { a } 11 / 03 / 97) \\
E W-C W \\
(11 / 14 / 96-03 / 11 / 97)\end{array}$ & $\begin{array}{c}\text { DP } \\
12 / 11 / 97 \\
E W \\
(11 / 12 / 97)\end{array}$ & $\begin{array}{c}1 \text { o } \\
(11 / 03 / 97 \text { a } 12 / 11 / 97) \\
1^{\text {st autumn-winter-spring }} \\
(03 / 11 / 97-11 / 12 / 97)\end{array}$ & $\begin{array}{c}2^{\mathrm{o}} \text { outono-inverno-primavera } \\
(23 / 05 / 98 \text { a } 14 / 11 / 98) \\
2^{\text {nd }} \text { autumn-winter-spring } \\
(05 / 23 / 98-11 / 14 / 98)\end{array}$ & $\begin{array}{c}\text { DP aos } 2 \text { anos } \\
(14 / 11 / 96 \text { a } 14 / 11 / 98) \\
\text { EW to } 2 \text { years old } \\
(11 / 14 / 96-11 / 14 / 98)\end{array}$ \\
\hline $\begin{array}{l}\text { DC (180 dias }) \\
C W \text { (180 days })\end{array}$ & $0,595 \mathrm{a}$ & 0,420 & 0,331 & $0,775 a$ & 0,450 \\
\hline $\begin{array}{l}\text { DP (70 dias) } \\
E W(70 \text { days })\end{array}$ & $0,444 b$ & 0,387 & 0,363 & $0,941 \mathrm{~b}$ & 0,453 \\
\hline
\end{tabular}

Médias seguidas de mesma letra, na mesma coluna, não diferem $(P>0,05)$ pelo $F$-teste.

Means followed by the same letter, in the same column, do not differ $(P>0.05)$ by F-test.

Tabela 3 - Pesos vivos ao abate, pesos líquidos de carcaça quente (PLC), rendimento de carcaça quente (RCQ), conformação ( $\mathrm{Sc}=$ subconvexo, $\mathrm{Re}=$ retilínea, $\mathrm{Sr}=$ sub-retilínea) e acabamento de carcaça $(\mathrm{mm}$ de gordura) dos novilhos do desmame precoce e do desmame convencional aos 2 anos de idade

Table 3 - Slaughter body weights $(S B W)$, net hot carcass weight $(C N W)$, hot carcass yield $(C Y)$, conformation $(S c=$ subconvex, St $=$ straight, Subco $=$ subconcave) and finishing fat thickness $(\mathrm{mm})$ of steers with two years old submitted to early weaning $(E W)$ or conventional weaning (CW)

\begin{tabular}{|c|c|c|c|c|c|c|c|c|c|c|}
\hline \multirow[t]{2}{*}{$\begin{array}{l}\text { Tratamento } \\
\text { Treatment }\end{array}$} & \multirow[t]{2}{*}{$\begin{array}{l}\text { PVA } \\
S B W\end{array}$} & \multirow[t]{2}{*}{$\begin{array}{l}\text { PLC }(\mathrm{kg}) \\
C N W\end{array}$} & \multirow[t]{2}{*}{$\begin{array}{c}\text { RCQ }(\%) \\
\qquad Y\end{array}$} & \multicolumn{3}{|c|}{$\begin{array}{l}\text { Conformação }{ }^{1} \\
\text { Conformation }\end{array}$} & \multicolumn{4}{|c|}{$\begin{array}{l}\text { Acabamento }^{1}(\mathrm{~mm}) \\
\text { Fat thickness }\end{array}$} \\
\hline & & & & $\mathrm{ScSc}$ & $\operatorname{Re}(\mathrm{St})$ & $\mathrm{Sr}$ (Subco) & 1 & 2 & 3 & 4 \\
\hline $\begin{array}{l}\text { DC (180 dias }) \\
C W \text { (180 days })\end{array}$ & 408,5 & 219,1 & 53,2 & 0 & 9 & 1 & 1 & 8 & 1 & 0 \\
\hline $\begin{array}{l}\mathrm{DP}(70 \text { dias }) \\
E W(70 \text { days })\end{array}$ & 411,2 & 219,6 & 52,4 & 2 & 3 & 2 & 1 & 3 & 2 & 1 \\
\hline
\end{tabular}

Médias seguidas de mesma letra, na mesma coluna, não diferem $(P>0,05)$ pelo teste $F$.

${ }^{1}$ Número de animais para conformação de carcaça e acabamento.

Means followed by the same letter, in a column, do not differ $(P>0.05)$ by F-test.

${ }^{1}$ Number of animals used for carcass conformation and fat thickness measurements.

\& Lobato (1994), em bezerros desmamados aos 100 dias ou 150 dias de idade e abatidos aos 2 anos de idade, não obtiveram diferenças nos pesos líquidos (224,5 e 223,1 kg, respectivamente) e nos rendimentos de carcaça $(56,1 \%)$.

Apesar das diferenças observadas no peso vivo e no ganho médio diário entre os períodos de desmame até 1 ano de idade, os novilhos do desmame precoce tiveram desempenhos ao abate estatisticamente semelhantes aos dos animais do desmame convencional.

Não houve efeitos significativos da idade de desmame sobre o acabamento, a conformação e a classificação de carcaça "Cota Hilton", comprovando que os bezerros do desmame precoce tiveram acabamento e conformação de carcaça semelhantes aos do desmame precoce. Na classificação do acabamento de carcaça ( 1 a 4 mm de gordura), 80,0 e $42,8 \%$ dos animais do desmame convencional e do desmame precoce, respectivamente, apresentaram $2 \mathrm{~mm}$ de espessura de gordura.

Vaz \& Restle (2002), em animais machos Braford desmamados aos 72 ou aos 210 dias de idade e terminados em confinamento aos 14 meses de idade, observaram que a carne dos animais apresentou características sensoriais semelhantes, confirmando que os dois manejos são ade- quados para a produção de machos superprecoces. Neste estudo, 71,4\% dos novilhos do grupo desmame precoce apresentaram carcaça com conformação entre subconvexa e retilínea e, em 90,0\% daqueles do desmame convencional, as carcaças tiveram classificação retilínea e não diferiram ( $\mathrm{P}>0,05)$ entre as idades de desmame.

Pötter \& Lobato (2003), em pesquisa com bezerros desmamados aos 100 e aos 180 dias de idade, determinaram aos 13-14 meses de idade pesos de abate e de carcaça inferiores $(\mathrm{P}<0,05)$ para os novilhos do desmame precoce, em comparação àqueles do desmame convencional (328,8 e 359,4 kg de PV e 174,0 e 186,7 kg de carcaça fria para desmame precoce e desmame convencional, respectivamente). Os novilhos do desmame precoce tiveram rendimento superior $(52,9 \%)$ ao daqueles do desmame convencional $(51,9 \%)$, mas não diferiram $(\mathrm{P}>0,05)$ quanto à espessura de gordura subcutânea. Os novilhos do desmame precoce foram abatidos, em média, aos 430,1 dias de idade e os do desmame convencional aos 416,9 dias de idade.

Neste experimento, oito carcaças do desmame convencional $(80,0 \%)$ foram classificadas como "Cota Hilton", enquanto, entre os animais do desmame precoce, apenas quatro tiveram a mesma classificação $(57,1 \%)$. Em experi- 
mento com novilhos abatidos aos 2 anos de idade, Albospino \& Lobato (1994), classificaram como "Cota Hilton" 77\% dos animais desmamados aos 100 dias de idade e apenas $66 \%$ dos desmamados aos 150 dias.

Neste experimento, os animais desmamados precocemente e alimentados adequadamente nos dois períodos de inverno-primavera apresentaram ganhos compensatórios que possibilitaram desenvolvimento e características de carcaça aos 2 anos de idade semelhantes aos daqueles desmamados à idade convencional ( \pm 7 meses). Assim, em sistemas pecuários com cria, recria e terminação com excesso de carga animal por hectare (Gottschall \& Lobato, 1996; Simeone \& Lobato, 1996) e com vacas com baixa condição corporal (Pio de Almeida et al., 2002), o desmame precoce permite acréscimos consideráveis na taxa de prenhez (Lobato \& Barcellos, 1992; Simeone \& Lobato, 1996), necessários para a maior eficiência dos sistemas pecuários (Beretta et al., 2002), sem ocasionar prejuízos na obtenção de novilhos precoces aos 2 anos de idade.

\section{Conclusões}

Até um ano de idade, bezerros desmamados precocemente, aproximadamente aos 70 dias de idade, e manejados em pastagem melhorada no primeiro inverno/primavera apresentam desenvolvimento inferior ao de animais desmamados à idade convencional.

Bezerros desmamados precocemente e mantidos em pastagem melhorada nos dois primeiros períodos de inverno/ primavera apresentam crescimento compensatório e atingem desenvolvimento aos 2 anos de idade semelhante ao obtido com desmame convencional.

Novilhos do desmame precoce são abatidos aos 24-27 meses de idade com pesos vivos e características de carcaça semelhantes aos de animais desmamados à idade convencional.

\section{Agradecimento}

Ao pesquisador da EMBRAPA/CNPPSUL-Bagé/RS, Eduardo Salomoni, pelo auxílio na classificação das carcaças dos novilhos.

\section{Literatura Citada}

ALBOSPINO, B.H.J.C.; LOBATO, J.F.P. Efeitos do desmame precoce de bezerros no desempenho até os 24-26 meses de idade. Revista Brasileira de Zootecnia, v.23, n.4, p.565575, 1994

ASSOCIATION OF OFICIAL ANALYTICAL CHEMIST - AOAC. Official methods of analysis. 12.ed. Washington, DC.: Committee on Editing Methods of Analysis, 1975. 1094p.
BERETTA, V.; LOBATO, J.F.P.; MIELITZ NETTO, C.G.A. Produtividade e eficiência biológica de sistemas de produção de gado de corte de ciclo completo no Rio Grande do Sul. Revista Brasileira de Zootecnia, v.31, n.2, p.991-1001, 2002 (supl.).

BERGAMASCHI, H.; GUADAGNIN, M.R. Agroclima da Estação Experimental Agronômica. Porto Alegre: Universidade Federal do Rio Grande do Sul, 1990. 96p.

BOLDRINI, I.I. Dinâmica de vegetação de uma pastagem natural sob diferentes níveis de oferta de forragem e tipos de solos, Depressão Central, RS. Porto Alegre: Universidade Federal do Rio Grande do Sul, 1993. 262p. Tese (Doutorado em Zootecnia) - Universidade Federal do Rio Grande do Sul, 1993.

BRASIL. Ministério da Agricultura. Departamento Nacional de Pesquisa Agropecuária. Divisão de Pesquisa Pedológica. Levantamento de reconhecimento dos Solos do estado do Rio Grande do Sul. Recife: 1973. 431p. (Boletim Técnico, 30).

BRASIL. Ministério da Agricultura. Portaria nº 612, de 05 de outubro de 1989. Aprova o novo sistema nacional de tipificação de carcaças bovinas. Diário Oficial da União, Brasília, p.18146, 10 out. 1989 . Seção 1 .

CACHAPUZ, J.M.; LOBATO, J.F.P.; LEBOUTE, E.M. Pastagens melhoradas e suplementos alimentares no comportamento reprodutivo de novilhas com primeira cria ao pé. Pesquisa Agropecuária Brasileira, v.25, n.3, p.445-454, 1990.

CARSTENS, G.E.; JOHNSON, D.E.; ELLENBERGER, M.A. et al. Physical and chemical components of the empty body during compensatory growth in beef steers. Journal of Animal Science, v.69, n.8, p.3251-3264, 1991.

DROUILLARD, J.S.; FERRELL, C.L.; KLOPFENSTEIN, T.J. e al. Compensatory growth following metabolic protein or energy restrictions in beef steers. Journal of Animal Science, v.69, n.2, p.811-818, 1991 .

FUNABA, M.; KAGIYAMA, K.; IRIKI, T. et al. Changes in nitrogen balance with age in calves weaned at 5 or 6 weeks of age. Journal of Animal Science, v.72, n.3, p.732-738, 1994.

GARDNER, A.L. Estudio sobre métodos agronómicos para la evaluación de pastures. Montevideo: CIAAB, MGA, IICA, 1967. 120p.

GOMEZ, K.A.; GOMEZ, A.A. Statistical procedures for agricultural research. 2.ed. New York: John Wiley, 1984. $680 \mathrm{p}$.

GOTTSCHALL, C.S.; LOBATO, J.F.P. Comportamento reprodutivo de vacas de corte de primíparas submetidas a três lotações em campo nativo. Revista Brasileira de Zootecnia, v.25, n.1, p.46-57, 1996.

LOBATO, J.F.P.; BARCELLOS, J.O.J. Efeitos da utilização de pastagem melhorada no pós-parto e do desmame aos $100 \mathrm{ou}$ 180 dias de idade no desempenho reprodutivo de vacas de corte. Revista Brasileira de Zootecnia, v.21, n.3, p.385-395, 1992.

MEYER, J.H.; HULL, J.L.; WEITKAMP, W.H. et al. Compensatory growth responses of fattening steers following various low energy intake regimes on hay or irrigated pasture. Journal of Animal Science, v.24, n.1, p.29-37, 1965

MORAES, A.A.S.; LOBATO, J.F.P. Efeito de duas idades de desmame no desenvolvimento de bezerros de corte. Revista Brasileira de Zootecnia, v.22, n.6, p.885-892, 1993.

O'DONOVAN, P.B.; CONWAY, A.; O'SHEA, J.A. Study of the herbage intake and efficiency of feed utilization of grazing cattle previously fed two winter planes of nutrition. Journal of Agriculture Science, v.78, n.1, p.87-95, 1972.

PHILlIPS, W.A.; HOLLOWAY, J.W.; COLEMAN, S.W. Effect of pre and post weaning management system on the performance on Brahman crossbred feeder calves. Journal of Animal Science, v.69, n.8, p.3102-3111, 1991.

PIO DE ALMEIDA, L.S.; LOBATO, J.F.P.; SCHENKEL, F.S. Data de desmame e desempenho reprodutivo de vacas de corte. Revista Brasileira de Zootecnia, v.31, n.3, p.1223-1229, 2002 
PIO DE ALMEIDA, L.S.; LOBATO, J.F.P.; SCHENKEL, F.S. Idade de desmame e suplementação no desenvolvimento e em características de carcaças de novilhos de corte. Revista Brasileira de Zootecnia, v.32, n.6, p.1713-1721, 2003 (supl.1).

POPPI, D.P.; McLENNAN, S.R. Protein and energy utilization by ruminants at pasture. Journal of Animal Science, v.73, n.1, p.278-290, 1995 .

PÖTTER, B.A.A.; LOBATO, J.F.P. Desempenho e características quantitativas de carcaça de novilhos Braford desmamados aos 100 ou 180 dias de idade e abatidos aos 13-14 meses. Revista Brasileira de Zootecnia, v.32, n.5, p.1220-1226, 2003.

RESTLE, J.; POLLI, V.A.; ALVES FILHO, D.C. et al. Desenvolvimento de bovinos de corte de diferentes grupos genéticos desmamados aos 3 ou 7 meses de idade. Revista Brasileira de Zootecnia, v.28, n.5, p.1023-1030, 1999a.

RESTLE, J.; VAZ, F.N.; BRONDANI, I.L. et al. Estudo da carcaça de machos braford desmamados aos 72 ou 210 dias, abatidos aos catorze meses. Pesquisa Agropecuária Brasileira, v.34, n.11, p.2137-2144, 1999b.

ROVIRA, J.M. Manejo nutritivo de los rodeos de cría en pastoreo. Montevideo: Hemisferio Sur, 1996. 288p.

STATISTICAL ANALYSIS SYSTEM - SAS. SAS/STAT: user's guide. 11.ed. Cary: 1996. (CD-ROM).

SHORT, R.E.; BELLOWS, R.A.; STAIGMILLER, R.B. et al. Physiological mechanisms controlling anestrus and infertility in postpartum beef cattle. Journal Animal Science, v. 68 n.3, p.799-816, 1990

SIMEONE, A.; LOBATO, J.F.P. Efeito da lotação animal em campo nativo e do controle da amamentação no comportamento reprodutivo de vacas de corte primíparas. Revista Brasileira de Zootecnia, v.25, n.6, p.1216-1227, 1996.

SIMEONE, A.; LOBATO, J.F.P. Efeitos da carga animal em campo nativo e do controle da amamentação no desenvolvimento de bezerros mestiços até um ano de idade. Revista Brasileira de Zootecnia, v.27, n.1, p.179-185, 1998.

VAZ, F.N.; RESTLE, J. Aspectos qualitativos da carcaça e da carne de machos braford superprecoces, desmamados aos 72 ou 210 dias de idade. Revista Brasileira de Zootecnia, v.31, n.5, p.2078-2087, 2002.

WILLIAMS, G.L.; GAZAL, O.S.; GUZMAN, V. et al. Mechanisms regulating suckling-mediated anovulation in the cow. Animal Reproduction Science, v.42, n.1-4, p.289-297, 1996. 